\title{
SOCIAL SUPPORT ON FACEBOOK: THE INFLUENCE OF TIE STRENGTH AND GENDER DIFFERENCES
}

\author{
Pin Luarn \\ National Taiwan University of Science and Technology
}

No.43, Sec. 4, Keelung Rd., Da'an Dist., Taipei 106, Taiwan (R.O.C.)

luarn@mail.ntust.edu.tw

Hsien-Chih Kuo

National Taiwan University of Science and Technology

No.43, Sec. 4, Keelung Rd., Da'an Dist., Taipei 106, Taiwan (R.O.C.)

kuoandy302@gmail.com

Yu-Ping Chiu

National Taiwan University of Science and Technology

No.43, Sec. 4, Keelung Rd., Da'an Dist., Taipei 106, Taiwan (R.O.C.) d9808105@mail.ntust.edu.tw

Shu-Chen Chang

National Taiwan University

No. 1, Sec. 4, Roosevelt Road, Taipei, 10617, Taiwan(R.O.C)

s79536117@gmail.com

\section{ABSTRACT}

How do people define their online relationships? Do "friends" still offer social support to each other on Facebook? This article discusses the effects of tie strength and gender difference on social support for online friendships. The results showed that individuals with strong ties have a significantly higher frequency of clicking "like," and posting comments and messages on Facebook than individuals with weak ties do. In addition, females have a significantly higher frequency of liking, commenting and messaging than males. The results reconfirm the gender difference of social support in sociology and reveal the pattern behind user behavior on a social network website. These findings could be applied to the value proposition and to the design of interaction tools of social network websites in the future.

Keywords: Social Support, Relationship, Tie Strength, Gender, Facebook 


\section{INTRODUCTION}

Friend may be a term that now has to be redefined. Social network sites (SNSs) are changing the behavior of Internet users ${ }^{1,2}$. The appearance of SNSs has changed the form of information from centralization and broadcasting into collaboration and sharing ${ }^{3}$. This change has made it easier for Internet users to communicate and maintain c their social relationships ${ }^{4}$. Carlota et al. ${ }^{1}$ and Obst and Stafurik ${ }^{5}$ have found that SNSs encourage interpersonal connections and increase the availability of social support through information sharing, guidance, and the friendships ${ }^{1}$. Social support is a concept in sociology that measures a person's sense of being cared for, responded to, and helped by people in his or her social groups ${ }^{6,7}$. Cheshire ${ }^{8}$ and Crocker and Canevello ${ }^{9}$ have described the SNSs as a platform for users to exchange social support. For example, Facebook users may obtain social support by clicking "like" and posting comments. The perception of social support in a SNSs not only contributes to the quality of relationships with friends, but also results in the intention to continue using the site ${ }^{10,11}$. Therefore, it is important to understand the social support prototype on SNSs to help website service providers improve their marketing strategies.

Facebook, the world's largest SNSs ${ }^{1}$, has more than 1 billion users who use it to connect with their friends and maintain their social networks. Through all kinds of interaction on Facebook, users may obtain social support by clicking "like," comment giving or private messaging. The clicking "like," as the most popular interaction on Facebook, means friends like your saying and click a like button on your text. It can be treated as an emotional support behavior ${ }^{12,13}$. The public comment giving and the private messaging mean friends make responses to you by texts or images. They can provide individuals to obtain social support through social interaction ${ }^{14}$. According to previous studies, strong social support makes people feel connected with their friends as well as building trust with those friends ${ }^{9,10}$. So, this study tried to measured social support by the clicking "like," comment giving and private messaging of Facebook and examined their relationships between tie strength, gender and social support.

To measure behavior of social support on Facebook, a program was designed to retrieve data of user interaction behaviors. Results showed that strong-tie social networks have higher proportion of social support behaviour, and female devoted more energy to manage and maintain their social network on Facebook. The gender result was confirmed by Kendler, Myers and Prescott ${ }^{15}$ and by Obst and Stafurik ${ }^{5}$. This research can be a foundation for future studies on effective marketing strategies for different gender group. 


\section{BACKGROUND LITERATURE}

\subsection{Social Support}

Social support is defined as the perception or experience that one is loved and cared for, esteemed and valued, and part of a social network of mutual assistance and obligations ${ }^{7}$. Individuals can provide social support through verbal and nonverbal expressions of emotion, information, or referral, all of which contribute to well-being and reduce stress and illness ${ }^{16,}$ 17, 18. Social support usually takes place within established, multi-dimensional, and dyadic personal relationships, but can also take place through informal social networks ${ }^{19}$. Strong social support makes a user feel connected to friends while building trust with those friends ${ }^{9,10}$. Liang et al. ${ }^{11}$ have suggested that better social support leads to better relationships, which can be applied to strengthen customer loyalty. With the development of Internet, social support can be provided and received in the form of computer-mediated communication (CMC). People no longer need to know each other or to communicate face-to-face $(\mathrm{FtF})$ to obtain social support ${ }^{20,21}$ Unlike FtF support relationships, most CMC support exchanges begin by discussing the topic of concern, immediately and often in very personal terms. For example, Liang et al. ${ }^{11}$, Obst and Stafurik ${ }^{5}$ and Taylor et al. $^{22}$ have claimed that social support is an important social value that Internet users can obtain from an online community.

With the popularity of SNSs, the Internet has become an important channel for social support ${ }^{8,11}$. People can share their shopping experiences and purchase information with their social circles on SNSs. Instead of writing direct responses, a "Like" can be a source of feedback and emotional support ${ }^{12,13}$. It provides warmth and reassurance that the recipient is valued and cared about. In addition, comment giving and private messaging behavior create and reinforce the social ties and friendships which can be sources of information and emotional support. If a user receives support from friends on SNSs, the user may also be feeling obligated to extent support as well ${ }^{11}$. Therefore, this study measured social support by clicking "like," giving comment and message on Facebook and then examined the relationships between tie strength and gender.

\subsection{The Effect of Tie Strength on Social Support}

Tie strength is an important idea in social network analysis. It explains the relationship strength and quality between two people ${ }^{23}$. Granovetter ${ }^{24}$ defined the strength of a social tie as a combination of the amount of time, emotional intensity, intimacy, and reciprocal services devoted to a relationship, with all these factors being independent but correlated. For decades, researchers have used this definition to examine interactions 
between social ties and media usage $\mathrm{e}^{20,25}$ and how different relationships affect people and organizations ${ }^{23,}{ }^{26}$ Xiang, Neville and Rogati ${ }^{27}$ suggested that tie strengths affect the nature and frequency of online interactions between pairs of users. It is a positive and symmetrical relationship, and the ties can be strong or weak.

Strong ties are formed with close friends and overlapping social circles 24,25 . Therefore, we share and exchange the most intimacy with the friends with whom we have the strongest ties; we enjoy more and higher self-disclosure, emotional and instrumental exchanges, frequent interaction, reciprocity and time commitment with them ${ }^{20,28}$. These frequent interactions and time commitment not only offer emotional support and information to users $^{24,29,30}$, but also circulate information across their network of friends and therefore enhance access to help when necessary ${ }^{28}$. That is, strong ties provide powerful social support that not only improves mental health ${ }^{31}$ but also enables people to withstand crisis $^{29}$. In contrast, weak ties elicit creativity, finding a job ${ }^{32}$ and enliven the knowledge communication in the group $^{33}$. Weak ties make it even more possible to connect distinct groups and individuals ${ }^{24}$. According to previous research, information spread out far and across much more social distance (path length) through weak tie ${ }^{34}$. Although a large network of weak ties via Facebook becomes a source of social capital ${ }^{35}$, the quality of social support from weak tie relationship is questionable. From the aspect of tie strength, this study attempts to clarify whether the stronger the tie, the stronger the social support. Therefore, this study proposes the following hypothesis:

\section{H1: Individuals on Facebook with strong ties provide more social support to each other than individuals with weak ties.}

\subsection{The Effect of Gender on Social Support}

Previous studies have illustrated that interpersonal relationships are different for males and females, due to the differences in gender schema, identity and self-presentation ${ }^{15,36,37}$. In the face-to-face setting, females generally disclose more personal information and strive to develop their personal ties than males do. In the computer-mediated-communication setting, females' online behavior is more interpersonal ${ }^{38}$. The female characteristics that are relevant to social support interactions are nurturance and affiliation; females appear to have larger, more multifaceted, networks-oriented social relationships. That is, females have a wider variety of friends, each of whom has several functions. Females are more likely to seek and receive emotional support than males are ${ }^{38}$. Generally, females spend more time talking, discussing personal issues, and supporting each other. Females are more likely to enjoy social activities such as going out 
with their friends than non-social activities such as gambling, watching football games on TV, or exercising. In contrast, males' online behavior is more task- and information-oriented ${ }^{39}$. Males enjoy activities, such as golf or other leisure activities with their friends ${ }^{36}$. Males need a reason to get together. Reevy and Maslach ${ }^{38}$ suggested that males are independent and self-confident and do not rely much on others. When dealing with adversity, males may rely on friends, but their interactions are likely to focus on shared activities or distractions ${ }^{40}$. In summary, females get together for social interaction, but males get together to perform specific tasks.

Females are more sensitive than males to the ways others look at them, and tend to change their behavior to ensure a smooth interaction ${ }^{41,42}$, intimacy, connection and support ${ }^{43}$. Females might become depressed if they do not receive positive feedback from others, so they are more willing to change their behavior to make a better impression ${ }^{15}$. This behavior may also appear on SNSs. Sveningsson ${ }^{44}$ found that female self-presentations on SNS were more related to relationships and feelings, while those of males focused on status and technology. Therefore, to obtain optimal social experience on Facebook, females would have a higher frequency of interaction, such as text posting or social disclosure than males ${ }^{45}$. However, the social relationship of male, more independent than female, is task-oriented. Without a specific task to perform, males have little interest in using Facebook to provide social support to each other. It also means that females place a high priority on interpersonal communication, giving and receiving more social support on Facebook than males. On the basis of our theorizing, this study posits that:

H2: Females on Facebook provide more social support to each other than do males on Facebook.

\section{RESEARCH METHOD}

\subsection{Program Development}

To examine the roles of tie strength and gender in online social support on Facebook, a program with an online questionnaire based on the Facebook application was developed. The program was developed using PHP and JavaScript as programming language to operate on Microsoft Windows Server 2008 R2 Standard, Apache, and MySQL, provided by the AppServ 2.5.9 installer package. To access the social network dataset on Facebook, the program used the Facebook Software Development Kit (SDK) and the Facebook Query Language (FQL) object to connect to the Facebook accounts of participants and access their basic information and interaction records. Participants were requested to permit the program to access their Facebook 
account. After the participants did so, questionnaires were used to measure the participants' use of this platform to evaluate their Facebook friendships.

\subsection{Procedure}

The experiment consisted of several stages. In the first stage, this study recruited participants who then logged onto the program using their Facebook account and granted permission to allow the collection of user basic information and interaction records on Facebook. Second, after authorizing the program, participants were asked to rate their several Facebook friendship in 10 minutes, as in previous studies (e.g., Gilbert and Karahalios $^{26}$ ). The questionnaire had five questions and participants were asked to assess their tie strength with each friendship. In addition to tie strength, information on the gender of the participant and of his or her friends was collected by the Facebook application. This study also used this application to collect interactive data, including "likes," comments and private messages. These data were used to analyze how tie strength and gender affect online social support. Finally, participants were thanked and given a small gift.

\subsection{Measurement}

Tie strength. The questionnaire on tie strength included five questions based on the way claimed by Gilbert and Karahalios ${ }^{26}$ that combine ideas from Granovetter ${ }^{24}$ and Marsden and Campbell ${ }^{46}$. The questions were: How strong is your relationship with this person? How would you feel about asking this friend to loan you $\$ 100$ or more? How helpful would this person be if you were looking for a job? How upset would you be if this person "unfriended" you? If you left Facebook for another SNS, how important would it be to bring this friend along? The questionnaire set a 0 to 100 degrees standard to distinguish strong from weak ties. A score of more than 50 is a strong tie; a score of less than 50 is a weak tie.

Social support. Verbal and nonverbal expressions of emotion, information, or referral, to help reduce one's uncertainty or stress are all belong to the behavior of social support ${ }^{17}$. Individuals on Facebook can use the "like," button, write a comment or sent s private message to create and reinforce social ties and friendships ${ }^{12,13,14}$ which can measure social support. Therefore, this study used Facebook SDK to connect with participants' Facebook account and request their permission to access basic information and interaction records on Facebook to evaluate their social support.

\section{RESULTS}

145 participants (68 men and 77 women) completed the questionnaire, resulting in 6477 relationship data records. The average age of the 
participants was 20.78 (S.D. $=0.98)$. Their average length of Internet was 3.2 years $(S . D .=1.01)$. To test hypotheses in this study, the independent sample t-test was adopted. Hypothesis 1 posited that individuals with strong ties provide more social support to each other than individuals with weak ties do. To examine H1, the relationship between tie strength and three types of social support (clicking "like," comment giving and private messaging) on Facebook were tested. The results suggested that individuals with strong ties have significantly higher frequency of clicking "like" ( $p<0.001)$, comment giving $(p<0.001)$ and private messaging $(p<0.001)$ on Facebook than individuals with weak ties (see Table 1). Accordingly, H1 was supported.

Table 1. The effect of tie strength on the frequency of interaction

\begin{tabular}{ccccccc}
\hline $\begin{array}{c}\text { Dependent } \\
\text { variable }\end{array}$ & $\begin{array}{c}\text { Independent } \\
\text { variable }\end{array}$ & $N$ & $M$ & S.D. & $t$ & $p$ \\
\hline Clicking & Strong tie & 3124 & 31.32 & 14.27 & 7.46 & .001 \\
"like" & Weak tie & 3353 & 12.14 & 13.74 & & \\
Comment & Strong tie & 3124 & 28.34 & 21.12 & 4.48 & .001 \\
giving & Weak tie & 3353 & 9.92 & 12.47 & & \\
Private & Strong tie & 3124 & 172.33 & 118.41 & 14.81 & .001 \\
messaging & Weak tie & 3353 & 40.73 & 35.62 & & \\
\hline
\end{tabular}

Note: $\mathrm{N}=$ number of the participants; $\mathrm{M}=$ means; $S . D .=$ standard deviation; $t=t$-value; $p=$ $p$-value

Hypothesis 2 posited that females provide more social support to each other on Facebook than males. To examine H2, the differences of three types of social support on Facebook between genders were tested. The results showed that females have significantly higher frequency of clicking "like" $(p$ $<0.001)$, comment giving $(p<0.001)$ and private messaging $(p<0.004)$ on Facebook than males (see Table 2). Accordingly, H2 was supported.

Table 2. The effect of the same-gender friend on the frequency of interaction

\begin{tabular}{ccccccc}
\hline $\begin{array}{c}\text { Dependent } \\
\text { variable }\end{array}$ & $\begin{array}{c}\text { Independent } \\
\text { variable }\end{array}$ & $N$ & $M$ & S.D. & $t$ & $p$ \\
\hline Clicking & Female & 2802 & 33.18 & 20.71 & 8.74 & .001 \\
"like" & Male & 3675 & 10.27 & 7.71 & & \\
Comment & Female & 2802 & 25.29 & 19.57 & 3.16 & .001 \\
giving & Male & 3675 & 12.26 & 14.73 & & \\
Private & Female & 2802 & 183.83 & 121.62 & 12.42 & .004 \\
messaging & Male & 3675 & 29.12 & 35.17 & & \\
\hline
\end{tabular}

Note: $\mathrm{N}=$ number of the participants; $\mathrm{M}=$ means; S.D. $=$ standard deviation; $t=t$-value; $p$ $=p$-value 


\section{DISCUSSION}

Social support is important in social network ties and social commerce because supportive interactions make social network members closer to one

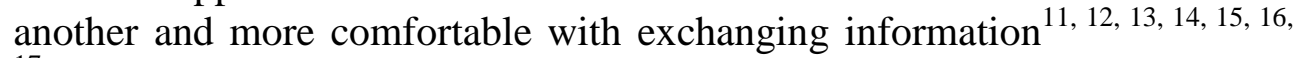
${ }^{17}$. This study used tie strength and gender to explain social support behavior on Facebook for marketing executer's disposition of their marketing resources. The results showed that individuals with strong ties have significantly higher frequency of clicking "like," writing comments and sending private messages on Facebook than individuals with weak ties. H1 was supported, the stronger the tie strength between individuals, the more support behavior they engage in ${ }^{20,28}$. When people have problems or need advice, their friends with strong tie offer more help and have more power to influence their decisions. Hypothesis 2 was also supported. Females have significantly higher frequency of "likes," comments and messages on Facebook than males do. The results verified that women have higher participation rates, higher frequency of posting and commenting to their friends $2,28,45$. This higher involvement made social support easier to exchange. This finding was consistent with earlier studies ${ }^{38}$.

The results of this study make several unique points. First, there are numerous studies of Facebook users' behavior and the information exchange but few studies of social support. Ryan and Xenos ${ }^{47}$ and Ross et $\mathrm{al}^{48}$ for example, have discussed the connection between Facebook user behavior and personality. Ellison, Steinfield and Lampe ${ }^{35}$ analyzed the benefits of Facebook friends, and found a positive relationship between certain kinds of Facebook use and the maintenance and creation of social capital. Social support, measured by informational and emotional support, has a significant positive effect on the intention to continue using the website and the intention to conduct social commerce ${ }^{11}$. Therefore, this research developed a program to retrieve data on user interactions to analyze the effect of social ties and gender on social support behavior on Facebook. In addition, this research has found that a higher proportion of social support behavior is found in strong-tie networks. Although many weak-tie networks exist and many advantages of weak-tie networks have also been revealed, these weak-tie has fewer interactions to provide social support on Facebook. Finally, as mentioned by Kendler, Myers and Prescot ${ }^{15}$, females have broader social networks and are more emotionally involved in those networks. Females are more sensitive to social support and are easily disappointed if they receive unexpected feedback. This research supports the finding that females devote more energy to managing and maintaining their social network. 
This study revealed the pattern behind user behavior on a SNSs. Such a pattern could be applied to value proposition and to the design of interaction tools. First, based on this study, social network service providers should adjust their value propositions to target acquaintances and females. The interaction and communication among acquaintances were shown to be more effective. Attracting female users may contribute to increasing the frequency of interaction. Second, this study concluded that females are more inclined to public interaction than males are. In order to increase the interaction in both female and male segments, SNS providers should use the female segment to underline their public interaction function, for example, the photos, pictures and stickers tools.

Through the SNSs, people have more access to various networks and can receive more information through interaction. This study examines the influence of tie strength and gender on social support. The results of this research could be a reference for future research on SNS user behavior and assist SNS service providers to present their value propositions and services more effectively. These findings can help enterprises and marketing executives to clarify their strategies to attract consumers.

\section{ACKNOWLEDGMENT}

This research was sponsored by the National Science Council of Taiwan, under the project number NSC 101-2410-H-011-002-

\section{REFERENCES}

[1] C. Lorenzo-Romero, M. Alarcon-del-Am, and E. Constantinides, Segmentation of users of social networking websites. Social Behavior and Personality, 40(3), p401-414, 2012. http://dx.doi.org/10.2224/sbp.2012.40.3.401.

[2] E. Kalampokis, E. Tambouris, and K. Tarabanis, Understanding the predictive power of social media. Internet Research, 23(5), p544-559, 2013.

[3] K. Wan, and G. Yu, The growing model of online communication network based on structural classification. Advances in Information Sciences and Service Sciences, 4(8), 2012.

[4] P. Obst, and J. Stafurik, Online we are all able bodied: Online psychological sense of community and social support found through membership of disability-specific websites promotes well-being for people living with a physical disability. Journal of Community \& Applied Social Psychology, 20(6), p525-531, 2010. http://dx.doi.org/10.1002/casp.1067.

[5] S. Cobb, Social support as a moderator of life stress. Psychosomatic 
medicine, 38(5), p300-314, 1976.

[6] JS. House, Work stress and social support. Reading, MA: Addison-Wesley, 1981.

[7] C. Cheshire, Selective incentives and generalized information exchange. Social Psychology Quarterly, 70(1), p82-100, 2007. http://dx.doi.org/10.1177/019027250707000109.

[8] J. Crocker, and A. Canevello, Creating and undermining social support in communal relationships: The role of compassionate and self-image goals. Journal of Personality and Social Psychology, 95(3), p555-575, 2008. http://dx.doi.org/10.1037/0022-3514.95.3.555.

[9] K. Weber, A. Johnson, and M. Corrigan, Communcating emotional support and its relationship to feelings of being understood, trust, and self-disclosure. Communication Research Reports, 21(3), p316-323, 2004. http://dx.doi.org/10.1080/08824090409359994.

[10] T.P. Liang, Y.T. Ho, and E. Turban, What drives social commerce: The role of social support and relationship quality. International Journal of Electronic Commerce, 16(2), p69-90, 2011. http://dx.doi.org/10.2753/JEC1086-4415160204.

[11] J. Raacke, and J. Bonds-Raacke, MySpace and Facebook: Applying the uses and gratifications theory to exploring friend-networking sites. Cyberpsychology \& behavior, 11(2), p169-174, 2008. http://dx.doi.org/10.1089/cpb.2007.0056.

[12] Z. Tufekci, Grooming, gossip, Facebook and MySpace: What can we learn about these sites from those who won't assimilate? Information, Communication \& Society, 11(4), p544-564, 2008. http://dx.doi.org/10.1080/13691180801999050.

[13] M.W. Newman, D. Lauterbach, S.A. Munson, P. Resnick, and M.E. Morris, It's not that I don't have problems, I'm just not putting them on Facebook: challenges and opportunities in using online social networks for health. Paper presented at the ACM 2011 conference on Computer supported cooperative work. Hangzhou, China, March 19-23, 2011. http://dx.doi.org/10.1145/1958824.1958876.

[14] K.S Kendler, J. Myers, and C.A. Prescott, Sex differences in the relationship between social support and risk for major depression: a longitudinal study of opposite-sex twin pairs. American Journal of Psychiatry, 162(2), p250-256, 2005.

[15] N.S. Coulson, Receiving social support online: An analysis of a computer-mediated support group for individuals living with irritable bowel syndrome. CyberPsychology \& Behavior, 8(6), p580-584, 2005. http://dx.doi.org/10.1089/cpb.2005.8.580.

[16] C.H. Lin, Exploring facets of a social network to explicate the status of social support and its effects on stress. Social Behavior and Personality: an international journal, 37(5), p701-710, 2009. 
http://dx.doi.org/10.2224/sbp.2009.37.5.701.

[17] N. Madjar, Emotional and informational support from different sources and employee creativity. Journal of Occupational and Organizational Psychology, 81(1), p83-100, 2008. http://dx.doi.org/10.1348/096317907X202464.

[18] T.L. Albrecht, and M.B. Adelman, Communicating social support. Thousand Oaks, CA, US: Sage Publications, Inc.,1987.

[19] J. Walker, S. Wasserman, and B. Wellman, Statistical models for social support networks. In S.Wasserman and J.Galaskiewicz (Eds.), Advances in social network analysis (p53-78). Thousand Oaks, CA : Sage, 1994.

[20] B. Xie, Multimodal Computer-mediated communication and social support among older Chinese Internet users. Journal of ComputerMediated Communication, 13(3), 728-750, 2008. http://dx.doi.org/10.1111/j.1083-6101.2008.00417.x.

[21] S.E. Taylor, D.K. Sherman, H.S. Kim, J. Jarcho, K. Takagi, and M.S. Dunagan, Culture and social support: who seeks it and why? Journal of personality and social psychology, 87(3), p354-362, 2004. http://dx.doi.org/10.1037/0022-3514.87.3.354.

[22] T. Nepusz, A. Petróczi, and F. Bazsó, Fuzzy Clustering and the Concept of Bridgedness in Social Networks. Paper Presented at the International Workshop and Conference on Network Science (NetSci), New York, USA, May 20-25, 2007.

[23] M.S. Granovetter, The strength of weak ties. American journal of sociology, 78(6), p1360-1380, 1973. http://dx.doi.org/10.1086/225469.

[24] C. Haythornthwaite, Strong, weak, and latent ties and the impact of new media. The Information Society, 18(5), p385-401, 2002. http://dx.doi.org/10.1080/01972240290108195.

[25] E. Gilbert, and K. Karahalios. Predicting tie strength with social media. Paper Presented at the SIGCHI Conference on Human Factors in Computing Systems, Boston, MA, USA, April 4-9, 2009. http://dx.doi.org/10.1145/1518701.1518736.

[26] R. Xiang, J. Neville, and M. Rogati, Modeling relationship strength in online social networks. Paper Presented at the 19th international conference on World wide web, Raleigh, NC, USA, April 26-30, 2010. http://dx.doi.org/10.1145/1772690.1772790.

[27] M. Granovetter, The strength of weak ties: A network theory revisited. Sociological theory, 1(1), p201-233, 1983.

[28] D. Krackhardt, and R.N. Stern, Informal networks and organizational crises: An experimental simulation. Social psychology quarterly, 151(2), p123-140, 1988. http://dx.doi.org/10.2307/2786835.

[29] B. Wellman, and S. Wortley, Different strokes from different folks: 
Community ties and social support. American journal of Sociology, 96(3), p558-588, 1990. http://dx.doi.org/10.1086/229572.

[30] C. Schaefer, J.C. Coyne, and R.S. Lazarus, The health-related functions of social support. Journal of behavioral Medicine, 4(4), p381-406, 1981. http://dx.doi.org/10.1007/BF00846149.

[31] D. Constant, L. Sproull, and S. Kiesler, The kindness of strangers: The usefulness of electronic weak ties for technical advice. Organization science, 7(2), p119-135, 1996. http://dx.doi.org/10.1287/orsc.7.2.119.

[32] M.T. Hansen, The search-transfer problem: The role of weak ties in sharing knowledge across organization subunits. Administrative $\begin{array}{llll}\text { science } & \text { quarterly, } & \text { 44(1), } & \text { p82-111, }\end{array}$ http://dx.doi.org/10.2307/2667032.

[33] F. Harary, R. Norman, and D. Cartwright, Structural models: An introduction to the theory of directed graphs. New York: Wiley, 1965.

[34] N.B. Ellison, C. Steinfield, and C. Lampe, The benefits of Facebook "friends:" Social capital and college students' use of online social network sites. Journal of Computer-Mediated Communication, 12(4), $\mathrm{p}$ 1143-1168, 2007. http://dx.doi.org/10.1111/j.1083-6101.2007.00367.x.

[35] K. Dindia, and M. Allen, Sex differences in self-disclosure: A meta-analysis. Psychological bulletin, 112(1), p106-124, 1992. http://dx.doi.org/10.1037/0033-2909.112.1.106.

[36] A.M. Manago, M.B. Graham, P.M. Greenfield, and G. Salimkhan, Self-presentation and gender on MySpace. Journal of Applied Developmental Psychology, 29(6), p446-458, 2008. http://dx.doi.org/ 10.1016/j.appdev.2008.07.001.

[37] G.M. Reevy, and C. Maslach, Use of social support: Gender and personality differences. Sex roles, 44(7-8), p437-459, 2001. http://dx.doi.org/10.1023/A:1011930128829.

[38] D. Tannen, You just don't understand: Women and men in conversation. London: Virago, 1991.

[39] S. Nolen-Hoeksema, Responses to depression and their effects on the duration of depressive episodes. Journal of abnormal psychology, $100(4)$, p569-582,

1991. http://dx.doi.org/10.1037//0021-843X.100.4.569.

[40] R. Schwarzer, and A. Leppin, Social support and health: A meta-analysis. Psychology and health, 3(1), p1-15, 1989. http://dx.doi.org/10.1080/08870448908400361.

[41] M.H. Davis, and S.L. Franzoi, Stability and change in adolescent self-consciousness and empathy. Journal of Research in Personality, 25(1), p70-87, 1991. http://dx.doi.org/10.1016/0092-6566(91)90006-C.

[42] B.M. DePaulo, J.A. Epstein, and M.M. Wyer, Sex differences in lying: How women and men deal with the dilemma of deceit. In Michael L. and Carolyn S. (Eds.), Lying and deception in everyday life (p126-147). 
New York, NY, USA: Guilford Press, 1993.

[43] M. Sveningsson Elm, Doing and undoing gender in a Swedish Internet community. In M. Sveningsson Elm and J. Sundén (Eds.), Cyberfeminism in Northern lights. Gender and digital media in a Nordic context (p104-129). Cambridge Scholars Publishing: Cambridge, 2007.

[44] M.G. Hoy, and G. Milne, Gender differences in privacy-related measures for young adult Facebook users. Journal of Interactive Advertising, 10(2), p28-45, 2010.

[45] P.V. Marsden, and K.E. Campbell, Measuring tie strength. Social forces, 63(2), p482-501, 1984. http://dx.doi.org/10.1093/sf/63.2.482.

[46] T. Ryan, and S. Xenos, Who uses Facebook? An investigation into the relationship between the Big Five, shyness, narcissism, loneliness, and Facebook usage. Computers in Human Behavior, 27(5), p1658-1664, 2011. http://dx.doi.org/10.1016/j.chb.2011.02.004.

[47] C. Ross, E.S. Orr, M. Sisic, J.M. Arseneault, M.G. Simmering, and R.R. Orr, Personality and motivations associated with Facebook use. Computers in Human Behavior, 25(2), p578-586, 2009. http://dx.doi.org/10.1016/j.chb.2008.12.024. 
